\title{
Pengembangan metode penilaian ganti rugi usaha pariwisata bahari akibat insiden pencemaran minyak di laut
}

\section{Development of compensation valuation method for marine tourism businesses due to oil spill incident at the sea}

Gatot Yulianto $^{\text {ab }}$, Ali Mashar ab, Sugeng H. Wisudo ${ }^{\text {bc }}$, Luluk D. W. Handayania, Irza A. Nur ${ }^{\mathrm{a}}$, Luisa F. Amalo ${ }^{\mathrm{a}}$, Prita A. Permatasari $^{\mathrm{a}}$, Vidya N. Trissanti ${ }^{\mathrm{a}}$, Marfian D. Putra ${ }^{\mathrm{a}}$, Yusli Wardiatno ${ }^{\text {ab }}$, Hefni Effendi ${ }^{\mathrm{ab}}$

\footnotetext{
${ }^{a}$ Pusat Penelitian Lingkungan Hidup, Lembaga Penelitian dan Pengabdian kepada Masyarakat, IPB University, Kampus IPB Dramaga Bogor, 16680, Indonesia

${ }^{\mathrm{b}}$ Departemen Manajemen Sumberdaya Perairan, Fakultas Perikanan dan Ilmu Kelautan, IPB University, Kampus IPB Dramaga Bogor, 16680, Indonesia [+62 251-8624360]

${ }^{\mathrm{c}}$ Departemen Pemanfaatan Sumberdaya Perikanan, Fakultas Perikanan dan Ilmu Kelautan, IPB University, Kampus IPB Dramaga Bogor, 16680, Indonesia
}

Article Info:

Received: 03 - 04 - 2021

Accepted: 03 - 06 - 2021

Keywords:

Compensation valuation, Karawang coast, oil spill, tourism businesses

Corresponding Author: Gatot Yulianto

Departemen Manajemen

Sumberdaya Perairan, Fakultas

Perikanan dan Ilmu Kelautan,

Institut Pertanian Bogor;

Tel. +62-251-8624360

Email:

gyo@apps.ipb.ac.id

\begin{abstract}
One of the coastal ecosystem functions is to produce environmental services that can be used for marine tourism. Oil pollution incidents at sea have caused a decline in the quality of marine tourism objects, thus reducing the number of visitors arriving. It has implications for decreasing the income of the people who do business in tourist areas. The community's claim for immediate compensation payments requires a faster calculation method. This research aims to develop a method of assessing the economic compensation for marine tourism businesses affected by oil pollution incidents at sea. The type of this research is descriptive research. The data consists of primary data and secondary data. The steps required in calculating compensation are (1) identifying tourism businesses, (2) building a theoretical concept of compensation, (3) determining the legal basis for calculating compensation, and (4) Designing a compensation formula. The application of the five compensation calculation formulas requires 18 variables. By taking the case of an oil spill incident in the North Sea of Karawang, which has an impact on Tanjung Pakis beach tourism, an estimate of the value of compensation (Rp/day) is obtained for the buoy rental service business is Rp 111323.08 , for bathroom services business is $R p 69$ 504.62, for food/beverage trading business on a small scale is Rp 71510.77 and for food/beverage trading business on a large scale is $R p 188$ 569.23. For the next stage, the implementation of compensation needs to be verified against the impacted community and the payment mechanism to be right on target.
\end{abstract}

How to cite (CSE Style $8^{\text {th }}$ Edition):

Yulianto G, Mashar A, Wisudo SH, Handayani LDW, Nur IA, Amalo LF, Permatasari PA, Trissanti VN, Putra MD, Wardiatno Y, Effendi H. 2021. Pengembangan metode penilaian ganti rugi usaha pariwisata bahari akibat insiden pencemaran minyak di laut. JPSL 11(2): 221-232. http://dx.doi.org/10.29244/jpsl.11.2.221-232. 


\section{PENDAHULUAN}

Wilayah pesisir memiliki arti penting bagi kehidupan manusia. Wilayah pesisir merupakan suatu wilayah peralihan antara daratan dan lautan (Dahuri et al., 2008). Di wilayah pesisir tersebut terdapat ekosistem penting yang merupakan natural capital dan berpotensi untuk pengembangan ekowisata, yaitu ekosistem mangrove, ekosistem terumbu karang, ekosistem padang lamun, ekosistem estuari dan ekosistem pantai berpasir. Dalam ekosistem pesisir terdapat berbagai jasad hidup (biotik) dan lingkungan fisik (abiotik) yang merupakan satu kesatuan yang tidak dapat dipisahkan, saling terkait, dan saling berinteraksi antara yang satu dengan yang lainnya (Dahuri et al., 2008) serta merupakan ekosistem yang dinamis dan mempunyai kekayaan habitat yang beragam serta saling berinteraksi antara habitat tersebut (Djunaedi, 2011). Ekosistem pesisir memproduksi jasa-jasa lingkungan yang bermanfaat bagi manusia. Ekosistem memproduksi jasa-jasa lingkungan dan jasajasa tersebut dapat dimanfaatkan oleh manusia guna memenuhi kesejahteraannya, sehingga mempunyai nilai ekonomi yang penting (Costanza et al., 2014) dan perlu dihitung nilainya (Liu et al., 2010). Perhatian terhadap jasa-jasa ekosistem semakin meningkat sejak adanya Millennium Ecosystem Assessment (MEA, 2005). Dalam suatu ekosistem, terdapat struktur dan fungsi-fungsi ekosistem yang merupakan prasyarat bagi tumbuhnya jasa-jasa eksosistem (ecosystem services) yang berfungsi sebagai provisioning services, regulating services dan culture services (Vihervaara et al., 2010). Sebagai penyedia jasa kultural, ekosistem pesisir dapat dikembangkan sebagai objek wisata alam yang merupakan natural capital dengan jenis wisata adalah wisata rekreasi.

Jasa-jasa ekosistem merupakan konsep dan tool yang digunakan dalam MEA (Millennium Ecosystem Assessment) dan suatu perubahan dalam ekosistem (termasuk ekosistem laut) akan mempunyai konsekuensi terhadap human well-being (MEA, 2005). Salah satu yang menyebakan perubahan ekosistem adalah perusakan lingkungan hidup. Kualitas eksosistem pesisir dapat menurun ataupun rusak yang disebabkan adanya pencemaran laut. Pencemaran laut adalah masuknya zat atau energi secara langsung maupun tidak langsung oleh kegiatan manusia ke dalam lingkungan laut termasuk daerah pesisir pantai, sehingga dapat menimbulkan akibat yang merugikan baik terhadap sumber daya alam hayati, kesehatan manusia, gangguan terhadap kegiatan di laut, termasuk perikanan dan penggunaan lain-lain, yang dapat menyebabkan penurunan tingkat kualitas air laut serta menurunkan kualitas tempat tinggal dan rekreasi (Mukhtasor, 2007). Salah satu penyebab pencemaran laut adalah kejadian pencemaran minyak 'oil spill' baik karena insiden kebocoran kegiatan pemboran lepas pantai (drilling) ataupun kecelakaan kapal tanker serta kebocoran pipa penyalur. Dilihat dari sumber pencemar, penyebab pencemaran minyak di laut tersebut dikategorikan sebagai point sources (sumber titik) mengingat sumber pencemaran dapat diketahui dengan jelas lokasi dan kegiatannya.

Dengan kejelasan point sources, sebab terjadinya pencemaran dan dampak yang ditimbulkannya baik terhadap lingkungan pesisir maupun masyarakat, maka pelaku pencemar harus bertanggung jawab terhadap tindakannya mencemari laut, antara lain melakukan perbaikan dan pemulihan lingkungan serta memberikan ganti rugi (kompensasi) kepada masyarakat terdampak yang terganggu mata pencahariannya. Hal ini sesuai dengan polluter pay principle sebagaimana dimaksud pada pasal 87 ayat 1 Undang-Undang Nomor 32 Tahun 2009 tentang Perlindungan dan Pengelolaan Lingkungan Hidup yang berbunyi: Setiap penanggung jawab usaha dan/atau kegiatan yang melakukan perbuatan melanggar hukum berupa pencemaran dan/atau perusakan lingkungan hidup yang menimbulkan kerugian pada orang lain atau lingkungan hidup wajib membayar ganti rugi dan/atau melakukan tindakan tertentu. Wisata bahari adalah wisata yang objek dan daya tariknya bersumber dari bentang laut (sea scape) maupun bentang darat pantai (coastal landscape) (Fandeli, 1996). Dari pengertian tersebut, dapat dijelaskan bahwa aktivitas wisata dapat dilakukan di darat (pantai) antara lain berjalan-jalan di pantai berpasir, berjemur dan menikmati pemandangan dan juga dilakukan di laut antara lain mandi, berenang dan memancing. Aktivitas wisata yang dilakukan tergantung dari potensi dan kualitas objek wisata baik pantai daratan maupun perairannya. Salah satu dampak pencemaran minyak adalah menurunnya kualitas objek wisata, antara lain perairan tercemar, sehingga tidak dapat digunakan untuk aktivitas wisata 'mandi' di laut, pasir tercemar dan kotor serta timbulnya kebauan (bau minyak). Dalam kondisi 
pantai tercemar berat dan dapat membahayakan kesehatan pengunjung wisata, maka objek wisata menjadi 'closed area'. Kondisi demikian berdampak terhadap menurunnya jumlah kunjungan wisata dan pada akhirnya berpengaruh terhadap berbagai jenis usaha pariwisata dan pendapatan masyarakat yang mengandalkan pengunjung wisata. Variabel jumlah pengunjung berpengaruh secara signifikan terhadap pendapatan masyarakat (Firdaus dan Juliansyah, 2019). Untuk mempertahankan pada tingkat pendapatan semula, pelaku usaha perlu diberikan ganti rugi dan karenanya perlu dilakukan metode perhitungan yang relatif lebih cepat untuk mengantisipasi klaim/tuntutan dan konflik sosial.

Penilaian ganti rugi terhadap usaha pariwisata bahari yang terdampak akibat pencemaran minyak di laut merupakan penilaian post-ante, sehingga perlu metode perhitungan yang disesuaikan dengan karakteristik usahanya yang bergantung pada kualitas dan amenity objek wisata, jumlah kunjungan yang tidak menentu serta mempertimbangkan landasan hukum penilaian ganti rugi. Dibandingkan dengan perhitungan ganti rugi dengan pendekatan analisis usaha (analisis finansial) akan membutuhkan waktu yang lebih lama untuk memperoleh data dan analisisnya, mengingat pendekatan ini perlu menguraikan komponen-komponen input dan output usaha. Tujuan paper ini adalah mengembangkan metode penilaian ganti rugi ekonomi (kompensasi) usaha pariwisata bahari yang terdampak akibat insiden pencemaran minyak di laut. Metode penilaian dan formula yang dihasilkan akan memberikan informasi awal besaran nilai ganti rugi bagi polluter sebelum direalisasikannya pemberian ganti rugi.

\section{METODE}

\section{Lokasi Studi Kasus dan Waktu Penelitian}

Lokasi studi kasus untuk penerapan formula kompensasi dilakukan terhadap Objek Wisata Pantai Tanjung Pakis, Desa Tanjung Pakis, Kecamatan Pakis Jaya, Kabupaten Karawang pada bulan September 2019.

\section{Metode Pengumpulan Data}

Jenis penelitian yang digunakan adalah penelitian deskriptif. Data yang dikumpulkan terdiri atas data primer dan data sekunder. Data primer diperoleh melalui pengamatan lapangan, wawancara berpedoman pada kuesioner dengan responden pelaku usaha pariwisata yang dipilih berdasarkan teknik purposive sampling dan snowball sampling untuk mengungkap fakta dan gambaran tentang menurunnya jumlah pengunjung wisata, terdampak tidaknya usaha yang dilakukan, besaran kompensasi yang diharapkan, lama dampak yang dirasakan. Oleh karena itu, variabel yang digunakan dalam membangun formula perhitungan kompensasi hanya berdasarkan pengakuan responden. Untuk menghindari bias jawaban nilai kompensasi yang dilebihlebihkan), peneliti menyatakan kepada responden bukan sebagai pihak yang akan membayar kompensasi. Selain itu dilakukan diskusi mendalam (in-depth interview) dengan tokoh masyarakat dan pengelola objek wisata. Data sekunder bersumber dari referensi dan instansi terkait.

\section{Metode Analisis Data}

Metode analisis data dilakukan dengan mengombinasikan analisis kualitatif dan kuantitatif. Analisis kualitatif dengan mengolah data hasil pengamatan, wawancara dan data literatur untuk mengungkap gambaran dan fenomena terjadinya pencemaran minyak yang berdampak kepada usaha pariwisata. Analisis kuantitatif dengan membangun formula ganti rugi yang disesuikan dengan kajian teoritis, peraturan yang berlaku serta karakteristik usaha pariwisata yang perolehan pendapatannya bergantung pada jumlah pengunjung dengan kedatangan yang tidak menentu. Metode perhitungan ganti rugi usaha pariwisata bahari yang terdampak akibat insiden pencemaran minyak di laut berdasarkan tahapan sebagai berikut: 


\section{Melakukan Identifikasi Usaha-Usaha Pariwisata}

Klasifikasi usaha pariwisata, termasuk usaha pariwisata bahari dalam kajian ini mengacu pada UndangUndang Nomor 10 Tahun 2009 tentang Kepariwisataan. Usaha pariwisata bahari adalah usaha yang menyediakan barang dan/atau jasa bagi pemenuhan kebutuhan wisatawan dan penyelenggaraan wisata dengan potensi lingkungan pantai dan laut sebagai daya tarik utama. Usaha pariwisata bahari meliputi usaha (mengacu pada pengertian usaha pariwisata pasal 14):

a. daya tarik wisata bahari adalah usaha yang kegiatannya mengelola daya tarik wisata alam (lingkungan pantai dan laut), daya tarik wisata budaya, dan daya tarik wisata buatan/binaan manusia, seperti fasiltas jalur tracking mangrove.

b. kawasan pariwisata bahari adalah usaha yang kegiatannya membangun dan/atau mengelola kawasan pantai dan laut dengan luas tertentu untuk memenuhi kebutuhan pariwisata.

c. jasa transportasi wisata bahari adalah usaha khusus yang menyediakan angkutan untuk kebutuhan dan kegiatan pariwisata, bukan angkutan transportasi reguler/umum.

d. jasa perjalanan wisata adalah usaha biro perjalanan wisata dan usaha agen perjalanan wisata. Usaha biro perjalanan wisata meliputi usaha penyediaan jasa perencanaan perjalanan dan/atau jasa pelayanan dan penyelenggaraan pariwisata, termasuk penyelenggaraan perjalanan ibadah. Usaha agen perjalanan wisata meliputi usaha jasa pemesanan sarana, seperti pemesanan tiket dan pemesanan akomodasi serta pengurusan dokumen perjalanan.

e. jasa makanan dan minuman adalah usaha jasa penyediaan makanan dan minuman yang dilengkapi dengan peralatan dan perlengkapan untuk proses pembuatan dapat berupa restoran, kafe, jasa boga, dan bar/kedai minum yang ditujukan untuk kebutuhan pengunjung wisata bahari.

f. penyediaan akomodasi adalah usaha yang menyediakan pelayanan penginapan yang dapat dilengkapi dengan pelayanan pariwisata lainnya bagi pengunjung wisata bahari. Usaha penyediaan akomodasi dapat berupa hotel, vila, pondok wisata, bumi perkemahan, persinggahan karavan, dan akomodasi lainnya yang digunakan untuk tujuan pariwisata bahari.

g. penyelenggaraan kegiatan hiburan dan rekreasi usaha penyelenggaraan kegiatan hiburan dan rekreasi merupakan usaha yang ruang lingkup kegiatannya berupa usaha seni pertunjukan, arena permainan, karaoke, bioskop, serta kegiatan hiburan dan rekreasi lainnya yang bertujuan untuk pariwisata bahari.

h. penyelenggaraan pertemuan, perjalanan insentif, konferensi, dan pameran adalah usaha yang memberikan jasa bagi suatu pertemuan sekelompok orang, menyelenggarakan perjalanan bagi karyawan dan mitra usaha sebagai imbalan atas prestasinya, serta menyelenggarakan pameran dalam rangka menyebarluaskan informasi dan promosi suatu barang dan jasa yang berskala nasional, regional, dan internasional.

i. jasa informasi pariwisata adalah usaha yang menyediakan data berita, feature, foto, video, dan hasil penelitian mengenai kepariwisataan yang disebarkan dalam bentuk bahan cetak dan/atau elektronik.

j. jasa konsultan pariwisata adalah usaha yang menyediakan saran dan rekomendasi mengenai studi kelayakan, perencanaan, pengelolaan usaha, penelitian, dan pemasaran di bidang kepariwisataan.

k. jasa pramuwisata adalah usaha yang menyediakan dan/atau mengoordinasikan tenaga pemandu wisata untuk memenuhi kebutuhan wisatawan dan/atau kebutuhan biro perjalanan wisata.

1. wisata tirta adalah usaha yang menyelenggarakan wisata dan olahraga air, termasuk penyediaan sarana dan prasarana serta jasa lainnya yang dikelola secara komersial di perairan laut, pantai, sungai, danau, dan waduk.

m. spa adalah usaha perawatan yang memberikan layanan dengan metode kombinasi terapi air, terapi aroma, pijat, rempah-rempah, layanan makanan/minuman sehat, dan olah aktivitas fisik dengan tujuan menyeimbangkan jiwa dan raga dengan tetap memperhatikan tradisi dan budaya bangsa Indonesia. 


\section{Membangun Konsep Teoritik Kampensasi Usaha Pariwisata Terdampak}

\section{Pendapatan usaha pariwisata}

Untuk menghitung rataan pendapatan bersih yang diperoleh dari suatu jenis usaha pariwisata tidaklah mudah mengingat usaha pariwisata tergantung dari jumlah pengunjung wisata yang kedatangannya terkait dengan hari libur dan waktu senggang (leisure time). Oleh karenan itu, dikenal adanya low season (seperti libur akhir pekan pada hari Sabtu atau Minggu), high season (seperti long weekend) ataupun peak season (musim puncak, musim liburan). Selain pada hari hari-hari libur tersebut, pada hari-hari biasa terdapat juga pengunjung yang berkunjung ke objek wisata. Dengan demikian, pendapatan yang diperoleh pelaku usaha pariwisata terbagi ke dalam pendapatan yang diperoleh pada hari-hari biasa dan pendapatan yang diperoleh pada hari libur. Perbedaan pendapatan mengacu pada hasil penelitian Fauzan (2018) yang dapat dilihat pada Tabel 1.

Tabel 1 Data pendapatan kotor perorangan pelaku usaha pariwisata di Kabupaten Wonosobo pada tahun 2016

\begin{tabular}{lccc}
\hline \multicolumn{1}{c}{ Lokasi Wisata } & $\begin{array}{c}\text { Hari Biasa } \\
\text { (Ribuan Rupiah) }\end{array}$ & $\begin{array}{c}\text { Akhir Pekan/ } \\
\text { Hari Libur } \\
\text { (Ribuan Rupiah) }\end{array}$ & $\begin{array}{c}\text { Rasio Antara Pendapatan } \\
\text { Hari Libur dan Hari Biasa }\end{array}$ \\
\hline Kalianget & 1000 & 1500 & 1.5 \\
Telaga Warna & 400 & 1000 & 2.5 \\
DPT & 400 & 1000 & 2.5 \\
Sikunir & 500 & 1000 & 2 \\
Rataan & 575 & 1125 & 2.13 \\
\hline
\end{tabular}

Sumber: Fauzan (2018) dan diolah

Dari Tabel 1, terlihat bahwa pendapatan kotor (omset) pelaku usaha wisata pada hari libur 2 kali lipat dari pendapatan kotor yang diperoleh pada hari-hari biasa. Para pelaku usaha pariwisata di objek wisata Kabupaten Wonosobo pada umumnya memperoleh pendapatan bersih sebesar $10 \%$ dari pendapatan kotor harian yang diperoleh (Fauzan, 2018).

Dari penjelasan tersebut di atas, perhitungan pendapatan usaha pariwisata yang dilakukan masyarakat perlu memperhitungkan jumlah pengunjung yang berkunjung ke objek wisata menurut hari-hari biasa dan hari libur.

\section{Pendekatan perhitungan ganti rugi}

Penghitungan terhadap kerugian yang diderita oleh masyarakat 'pelaku' usaha pariwisata akibat pencemaran minyak didasarkan pada komponen yang disebut sebagai compensable damage atau kerusakan yang dapat dikompensasi. Perhitungan berdasarkan pendekatan pendapatan (income approach) dengan penilaian semua komponen penyusun pendapatan dihitung menurut harga pasar (actual market price). Secara grafis konsep kompensasi atau ganti rugi diperlihatkan pada Gambar 1 dan 2. Gambar 1 memperlihatkan ketika objek wisata dalam kondisi closed area akibat insiden pencemaran minyak sejak saat mulai terpapar sampai dengan waktu berhentinya dampak dengan diterbitkannya surat keterangan/pernyataan dari instansi berwenang (antara lain KLHK) yang menyatakan bahwa pencemaran sudah tidak ada. Sebelum terjadinya insiden pencemaran, pendapatan usaha masyarakat sebesar OP, namun setelah terjadinya insiden pencemaran masyarakat tidak memperoleh pendapatan, karena tidak ada pengunjung yang datang ke objek wisata. Besarnya kompensasi yang diberikan sebesar ABCD. Gambar 2 memperlihatkan ketika objek wisata dalam kondisi terkena dampak namun tidak dalam kondisi closed area dan pengunjung masih tetap datang meskipun jumlahnya berkurang. Pada kondisi ini (sepanjang periode terdampak, AC) masyarakat tetap berusaha dengan asumsi bahwa penerimaan (omset) lebih besar dari biaya operasional dan pendapatan adalah flat (rata-rata) 
sepanjang periode pencemaran sebesar $\mathrm{AB}$ yang lebih kecil dari dari pendapatan sebelum pencemaran (OP). Besarnya kompensasi yang diberikan sebesar bidang ABCD.

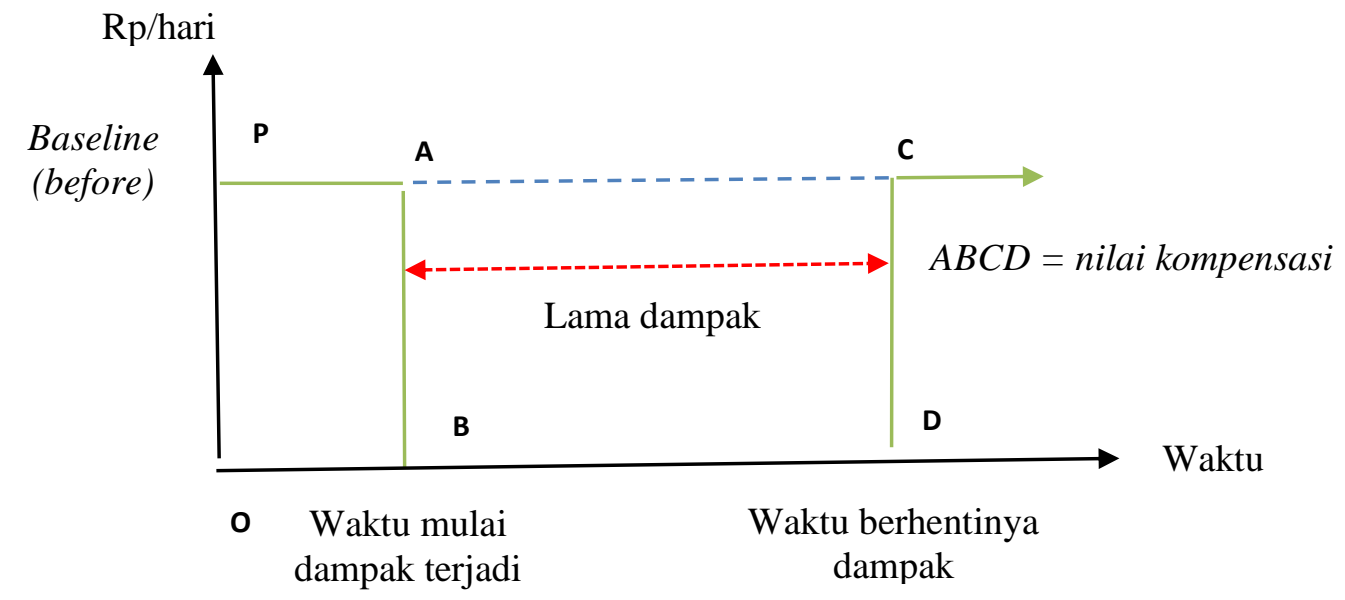

Gambar 1 Ilustrasi nilai kompensasi kasus tercemarnya objek wisata pantai dalam kondisi closed area

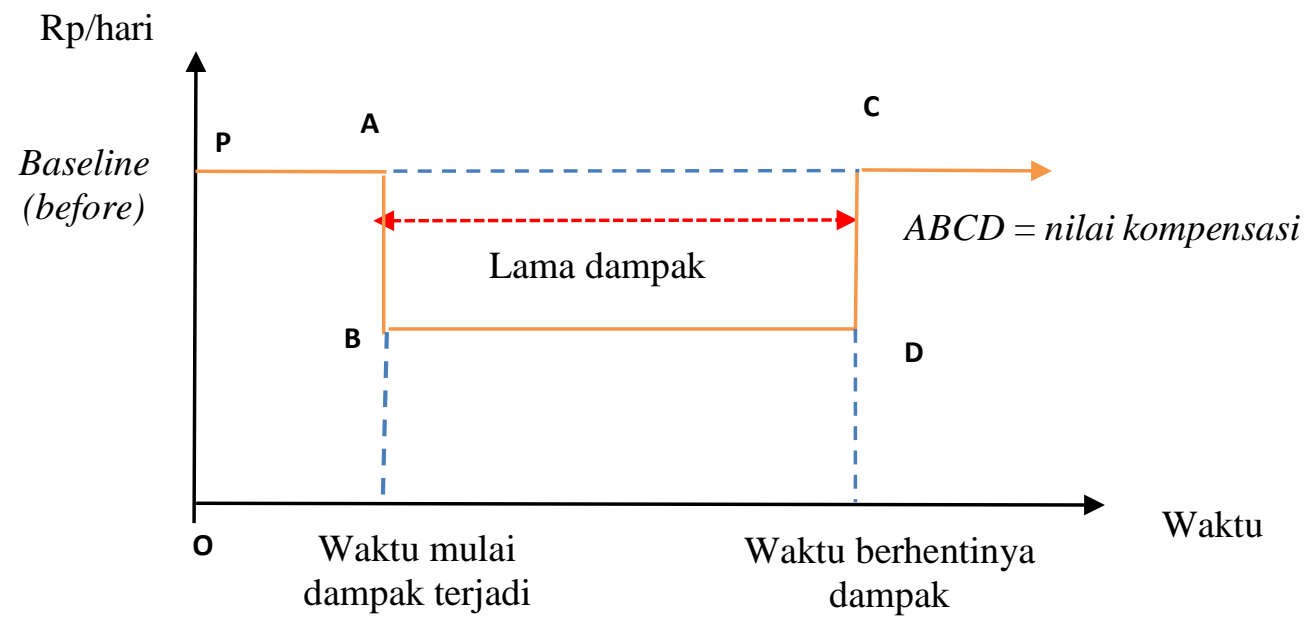

Gambar 2 Ilustrasi pemberian kompensasi kasus tercemarnya objek wisata pantai, namun masyarakat masih tetap menjalankan usahanya sepanjang periode terdampak

\section{Menentukan Dasar Hukum Perhitungan Kompensasi}

Acuan yang dijadikan dasar hukum untuk penghitungan estimasi kerugian masyarakat akibat pencemaran minyak adalah Peraturan Menteri Negara Lingkungan Hidup Nomor 7 tahun 2014 tentang Kerugian Lingkungan Hidup Akibat Pencemaran dan/atau Kerusakan Lingkungan Hidup, bahwa kompensasi atau ganti rugi akibat dampak cemaran adalah penggantian pendapatan masyarakat yang berkurang atau hilang sebagai akibat tercemarnya dan/atau rusaknya lingkungan selama periode terdampak. Pendapatan masyarakat yang dimaksud dalam peraturan tersebut adalah pendapatan bersih yang diperoleh dari penerimaan usaha dikurangi biaya produksi dan bukan merupakan omset serta tidak termasuk aset yang rusak akibat dampak pencemaran.

\section{Menentukan Formula Ganti Rugi Usaha Pariwisata Terdampak}

Pedekatan yang digunakan dalam perhitungan ganti rugi adalah pendapatan yang hilang (forgone earnings) yaitu nilai ekonomi dari pendapatan masyarakat yang berkurang atau hilang sebagai akibat 
tercemarnya dan/atau rusak lingkungan. Formula kompensasi/ganti rugi mengacu pada konsepsi bahwa perubahan (penurunan) pendapatan layak diberi ganti rugi yang dapat ditulis sebagai berikut:

Nilai kompensasi $=$ pendapatan sebelum pencemaran - pendapatan setelah pencemaran

Pada dasarnya penilaian kerugian berdasarkan pengakuan dan penghitungan masyarakat itu sendiri, menurut jumlah kerugian per satuan waktu atau siklus usaha (Rp/hari) dan lamanya dampak terjadi (hari) yang dimulai saat dampak terjadi sampai dengan berhentinya pencemaran. Pendapatan usaha pariwisata yang dilakukan oleh masyarakat diperoleh secara harian (Rp/hari). Dengan demikian, dari konsep kompensasi diturunkan formula sebagai berikut:

\section{Formula 1:}

dimana:

$$
\begin{aligned}
\mathrm{TCV}_{1} & =\left(\mathrm{I}_{b p}-\mathrm{I}_{a p}\right) \mathrm{L}_{d} \\
& =\left[\left\{\left(\beta_{b} \mathrm{I}_{b p B}+\rho_{b} \mathrm{I}_{b p L}\right) /\left(\beta_{b}+\rho_{b}\right)\right\}-\left[\left\{\left(\beta_{a} \mathrm{I}_{a p B}+\rho_{a} \mathrm{I}_{a p L}\right) /\left(\beta_{a}+\rho_{a}\right)\right\}\right] \mathrm{L}_{d}\right.
\end{aligned}
$$

TVC $=$ Total Nilai kompensasi $(\mathrm{Rp})$

$\mathrm{I}_{\mathrm{bp}} \quad=$ Rataan pendapatan bersih (keuntungan) sebelum pencemaran $(\mathrm{Rp} / \mathrm{hari})$

$\mathrm{I}_{\mathrm{ap}} \quad=$ Rataan pendapatan bersih (keuntungan) setelah pencemaran (Rp/hari)

$\mathrm{I}_{\mathrm{bpB}} \quad=$ pendapatan bersih (keuntungan) pada hari-hari biasa sebelum pencemaran (Rp/hari)

$\mathrm{I}_{\mathrm{bpL}} \quad=$ pendapatan bersih (keuntungan) pada hari-hari libur sebelum pencemaran (Rp/hari)

$\mathrm{I}_{\mathrm{apB}} \quad=$ pendapatan bersih (keuntungan) pada hari-hari biasa sesudah pencemaran $(\mathrm{Rp} / \mathrm{hari})$

$\mathrm{I}_{\mathrm{apL}} \quad=$ pendapatan bersih (keuntungan) pada hari-hari libur sesudah pencemaran (Rp/hari)

$\boldsymbol{\beta}_{\mathrm{b}} \quad=$ jumlah hari-hari biasa dalam sebulan dengan membuka usaha sebelum pencemaran (hari)

$\boldsymbol{\rho}_{\mathrm{b}} \quad=$ jumlah hari-hari libur dalam sebulan dengan membuka usaha sebelum pencemaran (hari)

$\boldsymbol{\beta}_{\mathrm{a}}=$ jumlah hari-hari biasa dalam sebulan dengan membuka usaha setelah pencemaran (hari)

$\boldsymbol{\rho}_{\mathrm{a}} \quad=$ jumlah hari-hari libur dalam sebulan dengan membuka usaha setelah pencemaran (hari)

$\mathrm{L}_{\mathrm{d}} \quad$ = Lama dampak (hari)

\section{Formula 2:}

$$
\begin{aligned}
\mathrm{TCV}_{2} & =\mathrm{r}\left(\mathrm{TR}_{b p}-\mathrm{TR}_{a p}\right) \mathrm{L}_{d} \\
& =\mathrm{r}\left[\left\{\left(\beta_{b} \mathrm{TR}_{b p B}+\rho_{b} \mathrm{TR}_{b p L}\right) /\left(\beta_{b}+\rho_{b}\right)\right\}-\left[\left\{\left(\beta_{a} \mathrm{TR}_{a p B}+\rho_{a} \mathrm{TR}_{a p L}\right) /\left(\beta_{a}+\rho_{a}\right)\right\}\right] \mathrm{L}_{d}\right.
\end{aligned}
$$

dimana :

$\mathrm{TR}_{\mathrm{bp}}=$ rataan pendapatan kotor/omset/penerimaan usaha sebelum pencemaran $(\mathrm{Rp} / \mathrm{hari})$

$\mathrm{TR}_{\mathrm{ap}}=$ rataan pendapatan kotor/omset/penerimaan usaha setelah pencemaran (Rp/hari)

$\mathrm{TR}_{\mathrm{bpB}}=$ pendapatan kotor/omset/penerimaan usaha pada hari-hari biasa sebelum pencemaran (Rp/hari)

$\mathrm{TR}_{\mathrm{bpL}}=$ pendapatan kotor/omset/penerimaan usaha pada hari-hari libur sebelum pencemaran (Rp/hari)

$\mathrm{TR}_{\mathrm{apB}}=$ pendapatan kotor/omset/penerimaan usaha pada hari-hari biasa setelah pencemaran (Rp/hari)

$\mathrm{TR}_{\mathrm{apL}}=$ pendapatan kotor/omset/penerimaan usaha pada hari-hari libur setelah pencemaran $(\mathrm{Rp} / \mathrm{hari})$

$\mathrm{r}=$ = Persentase keuntungan dari pendapatan kotor/omset/penerimaan usaha (\%)

Formula 3:

$\begin{aligned} \mathrm{TCV}_{3} & =\mathrm{I}_{b p} \operatorname{Re} \mathrm{L}_{d} \\ & =\left[\left(\beta_{b} \mathrm{I}_{b p B}+\rho_{b} \mathrm{I}_{b p L}\right) /\left(\beta_{b}+\rho_{b}\right)\right] \operatorname{Re} \mathrm{L}_{d}\end{aligned}$ 
dimana :

$\operatorname{Re}=$ Persentase penurunan pendapatan akibat pencemaran minyak $(\%$ per hari $)$

Formula 4:

Formula 5:

$$
\begin{aligned}
\mathrm{TCV}_{4} & =\mathrm{r}\left(\mathrm{TR}_{b p} \mathrm{Re}\right) \mathrm{L}_{d} \\
& =\left[\mathrm{r}\left\{\left(\beta_{b} \mathrm{TR}_{b p B}+\rho_{b} \mathrm{TR}_{b p L}\right) /\left(\beta_{b}+\rho_{b}\right)\right\} \mathrm{Re}\right] \mathrm{L}_{d}
\end{aligned}
$$

$$
\begin{aligned}
\mathrm{TCV}_{5} & =\mathrm{r}\left[\left(\tilde{\mathbf{V}}_{b p}-\tilde{\mathbf{V}}_{a p}\right) \mathrm{P}\right] \mathrm{L}_{d} \\
& =\mathrm{r}\left[\left\{\left(\beta_{b} \mathrm{~V}_{b p B}+\rho_{b} \mathrm{~V}_{b p L}\right) /\left(\beta_{b}+\rho_{b}\right)\right\} \mathrm{P}-\left\{\left(\beta_{a} \mathrm{~V}_{a p B}+\rho_{a} \mathrm{~V}_{a p L}\right) /\left(\beta_{a}+\rho_{a}\right)\right\} \mathrm{P}\right] \mathrm{L}_{d}
\end{aligned}
$$

dimana :

$\tilde{\mathbf{V}}_{\mathrm{bp}} \quad=$ Rata-rata jumlah pengunjung wisata; pembeli produk/jasa wisata; penyewa fasilitas wisata sebelum pencemaran (orang/hari)

$\tilde{\mathbf{V}}_{\text {ap }} \quad=$ Rata-rata jumlah pengunjung wisata; pembeli produk/jasa wisata; penyewa fasilitas wisata setelah pencemaran (orang/hari)

$\mathbf{V}_{\mathrm{bpB}}=$ jumlah pengunjung wisata; pembeli produk/jasa wisata; penyewa fasilitas wisata pada hari-hari biasa sebelum pencemaran (orang/hari)

$\mathbf{V}_{\mathrm{bpL}}=$ jumlah pengunjung wisata; pembeli produk/jasa wisata; penyewa fasilitas wisata pada hari-hari libur sebelum pencemaran (orang/hari)

$\mathbf{V}_{\mathrm{apB}}=$ jumlah pengunjung wisata; pembeli produk/jasa wisata; penyewa fasilitas wisata pada hari-hari biasa setelah pencemaran (orang/hari)

$\mathbf{V}_{\mathrm{zpL}}=$ jumlah pengunjung wisata; pembeli produk/jasa wisata; penyewa fasilitas wisata pada hari-hari libur sebelum pencemaran (orang/hari)

$\mathbf{P}=$ harga produk/tarif sewa fasilitas wisata (Rp/unit), biaya/pengeluaran rata-rata pengunjung untuk membeli produk di area wisata $(\mathrm{Rp} /$ pengunjung)

\section{HASIL DAN PEMBAHASAN}

\section{Daya Tarik Objek Wisata dan Akitivitas Pengunjung Wisata}

Objek wisata Tanjung Pakis mengandalkan panorama alam pantai (panoramic views), pantai berpasir, perairan yang jernih dan dapat untuk berenang mandi, menikmati cahaya matahari (sunny day) ataupun sekedar jalan-jalan di pantai. Selain itu, pengunjung dapat menikmati beragam makanan minuman 'kuliner', melihat aktivitas nelayan dan membeli cendera mata. Objek dan daya tarik wisata pantai Tanjung Pakis bersifat 'in situ' yang hanya dapat dinikmati di lokasi. Pada umumnya wisatawan kurang puas apabila tidak mendapatkan sesuatu objek secara utuh dan apa adanya, hal ini sesuai dengan pendapat Yoeti (2008) bahwa keputusan untuk memilih daerah tujuan wisata lebih banyak ditentukan oleh daya tarik wisata.

\section{Deskripsi Usaha-Usaha Pariwisata Terdampak}

Desain formula ganti rugi (persamaan 1 sampai dengan 5) perlu penerapan studi kasus usaha pariwisata. Di bawah ini diuraikan usaha pariwisata yang terdampak.

\section{Penyedia Jasa Pelampung Sewaan}

Salah satu aktivitas pengunjung di objek wisata pantai Tanjung Pakis, Desa Tanjung Pakis, Kecamatan Pakis Jaya, Kabupaten Karawang adalah mandi dan berenang di perairan pantai dengan menyewa pelampung. Aktivitas ini dalam bahasa setempat dikenal dengan nama nggebur. Setelah beberapa minggu sejak insiden pencemaran minyak di laut akhir bulan Juli 2019, Pantai Tanjung Pakis relatif sepi pengunjung akibat adanya larangan berenang dan kekhawatiran pengunjung untuk mandi dan berenang, karena adanya gumpalan minyak 228 
di pantai yang menimbulkan bau dan air tercemar. Dalam sebulan rata-rata 26 hari untuk bekerja dan setiap hari akhir pekan selalu berusaha karena pada saat tersebut pengunjung berwisata. Harga sewa ban pelampung seharga Rp 20000 untuk ban yang kecil dan Rp 25000 untuk ban yang besar. Sebelum terjadi tumpahan minyak, pada saat hari libur pemilik usaha penyewaan ban pelampung dapat menyewakan ban sebanyak 8 sampai dengan 15 unit per hari dan pada saat hari libur atau akhir pekan bisa mencapai 20 hingga 30 unit per hari. Penyedia jasa sewa pelampung memiliki pendapatan rata-rata sebesar Rp 150000 dengan rata-rata pendapatan pada hari biasa Rp 100 000, sedangkan pada hari libur Rp 625 000. Keuntungan bersih sekitar 70\% dari pendapatan (omset). Penurunan pendapatan akibat insiden kebocoran minyak sebesar 85 hingga 100\%. Dengan demikian, ganti rugi yang diberikan adalah sejumlah penurunan pendapatan berdasarkan turunnya pengunjung wisata yang menyewa pelampung tersebut. Pendapatan dengan lama terdampak selama 60 hari.

\section{Penyedia Jasa Kamar Mandi Bilas}

Setelah pengunjung wisata berenang/mandi di pantai kemudian mandi kembali (membilas) untuk membersihkan badan dan juga untuk buang air besar/kecil. Masyarakat setempat menyediakan jasa kamar mandi bilas, baik yang memliki 4 kamar ataupun 6 kamar. Dengan adanya insiden pencemaran minyak, pengunjung wisata Pantai Tanjung Pakis menurun. Pada beberapa minggu awal terjadinya insiden pencemaran, Pantai Tanjung Pakis sangat sepi pengunjung akibat diberlakukannya larangan mandi dan berenang. Pengunjung pun khawatir dengan adanya limbah di perairan. Pada akhir bulan Agustus, pengunjung berangsurangsur mulai datang kembali. Pada awal bulan Agustus, pendapatan pelaku usaha wisata hampir nihil, kemudian pada akhir bulan Agustus mereka mulai memiliki pendapatan sampai 15\% dari pendapatan normal, sehingga penurunan akibat insiden pencemaran minyak sebesar 85 hingga 100\%. Penyedia kamar bilas memiliki pendapatan normal Rp 125000 per hari dengan rata-rata pendapatan di hari biasa sekitar Rp 50000 per hari dan pada hari libur Rp 300000 per hari. Keuntungan bersih sekitar 70\% dari pendapatan kotor (omset) setelah dipotong dengan biaya kebersihan, perawatan, pengadaan air. Setelah terjadi insiden kebocoran minyak, pendapatan menjadi nihil. Dengan demikian ganti rugi yang diberikan adalah sejumlah penurunan pendapatan berdasarkan turunnya pengunjung wisata.

\section{Pedagang Makanan dan Minuman}

Masyarakat berjualan makanan dan minuman (warung kecil) di objek wisata, antara lain seperti kopi, es kelapa, minuman kemasan, makanan kecil (snack), gorengan, mie rebus dan lain-lain. Omset penjualan Rp 180000 pada hari biasa dan Rp 400000 pada hari libur. Untuk warung besar yang menyediakan ikan bakar dan berbagai jenis makanan dan minuman lainnya, mendapatkani omset penjualan yang lebih besar yakni sekitar Rp 300000 pada hari biasa dan Rp 1000000 sampai dengan Rp 1500000 pada hari libur. Sejak adanya insiden pencemaran minyak, omset turun sebesar $85 \%$ karena berkurangnya pengunjung wisata ke objek wisata, sehingga berimplikasi pada turunnya jumlah pembeli. Dengan demikian kompensasi yang diberikan adalah sejumlah penurunan pendapatan berdasarkan turunnya pengunjung wisata. Lama dampak yang diungkapkan responden sekitar 50 hari.

\section{Nilai Ganti Rugi Usaha Pariwisata Terdampak Pencemaran Minyak}

Daya tarik wisata akan menciptakan permintaan wisata yang dicerminkan dengan meningkatnya pengunjung wisata. Motif pengunjung wisata di Pantai Tanjung Pakis sebagian besar adalah rekreasi. Rekreasi merupakan kegiatan yang menyenangkan yang dimaksudkan untuk memulihkan kesegaran jasmani dan rohani, ingin menyegarkan dari keletihan dan kelelahan (Spillane, 1987; Soekadijo, 2000). Pengunjung sekedar melapas lelah dan menjauhkan dari kesibukan rutinitas dengan aktivitas sekedar berjalan-jalan santai di pantai (sight seeing), mandi di laut dan menikmati kuliner. Dengan adanya insiden pencemaran minyak di Laut Utara Karawang, menjadikan kualitas pantai menurun. Kondisi ini berimplikasi pada penurunan jumlah kunjungan wisata. Tentu saja usaha-usaha pariwisata yang dikelola masyarakat terkena dampaknya. 
Berdasarkan polluter pay principle, maka sudah menjadi kewajiban bagi pihak pencemar untuk membayar kompensasi. Namun dengan beragamnya jenis usaha pariwisata diperlukan metode perhitungan agar pihak pencemar secara cepat memperkirakan besarnya ganti rugi.

Terdapat 5 formula untuk menghitung ganti rugi. Pada dasarnya kelima formula tersebut digunakan untuk saling melengkapi mengingat keterbatasaan waktu, keterbatasan data dan pengetahuan pelaku usaha dalam memberikan informasi. Hampir setiap pertanyaan yang terkait dengan ganti rugi (willingness to accept) penilaian cenderung bersifat overvalue. Untuk mengaplikasikan kelima formula dibutuhkan 18 variabel yang datanya diperoleh dengan cara melakukan wawancara terhadap pelaku usaha terdampak. Selanjutnya, 18 variabel dan nilainya untuk 4 contoh kasus usaha pariwisata di objek wisata pantai Tanjung Pakis dapat dilihat pada Tabel 2.

Tabel 2 Nilai variabel yang digunakan dalam perhitungan ganti rugi

\begin{tabular}{ccccccc}
\hline No. & Variabel & Satuan & Usaha 1 & Usaha 2 & Usaha 3 & Usaha 4 \\
\hline 1 & $\beta_{b}$ dan $\beta_{a}$ & hari & 22 & 24 & 22 & 22 \\
2 & $\rho_{b}$ dan $\rho_{a}$ & hari & 4 & 4 & 4 & 4 \\
3 & $\mathrm{I}_{b p B}$ & Rp/hari & 70000 & 40000 & 60000 & 200000 \\
4 & $\mathrm{I}_{b p L}$ & Rp/hari & 350000 & 200000 & 250000 & 600000 \\
5 & $\mathrm{I}_{a p B}$ & Rp/hari & 0 & 10000 & 20000 & 60000 \\
6 & $\mathrm{I}_{a p B}$ & Rp/hari & 0 & 20000 & 30000 & 80000 \\
7 & $\mathrm{TR}_{b p B}$ & Rp/hari & 100000 & 80000 & 180000 & 350000 \\
8 & $\mathrm{TR}_{b p L}$ & Rp/hari & 600000 & 350000 & 400000 & 1400000 \\
9 & $\mathrm{TR}_{a p B}$ & Rp/hari & 0 & 10000 & 30000 & 60000 \\
10 & $\mathrm{TR}_{a p L}$ & Rp/hari & 0 & 20000 & 60000 & 200000 \\
11 & $\mathrm{r}$ & $\%$ & 60 & 70 & 30 & 30 \\
12 & $\mathrm{Re}$ & $\%$ & 100 & 90 & 85 & 85 \\
13 & $\mathrm{~V}_{b p B}$ & orang & 8 & 20 & 15 & 15 \\
14 & $\mathrm{~V}_{b p L}$ & orang & 20 & 50 & 40 & 30 \\
15 & $\mathrm{~V}_{a p B}$ & orang & 0 & 5 & 5 & 3 \\
16 & $\mathrm{~V}_{a p L}$ & orang & 0 & 10 & 15 & 5 \\
17 & $\mathrm{P}$ & Rp/unit & 20000 & 5000 & 10000 & 30000 \\
18 & $\mathrm{Ld}$ & hari & 60 & 50 & 50 & 50 \\
\hline
\end{tabular}

Keterangan: Usaha (1) penyedia jasa pelampung sewaan; usaha (2) penyedia jasa kamar mandi bilas; usaha (3) pedagang makanan dan minuman (skala kecil); usaha (3) pedagang makanan dan minuman (skala besar)

Tabel 3 Penurunan pendapatan (Rp/hari) dan nilai ganti rugi usaha pariwisata selama periode terdampak (Rp) akibat pencemaran minyak di laut per satu jenis usaha

\begin{tabular}{ccccc}
\hline Formula & Usaha 1 & Usaha 2 & Usaha 3 & Usaha 4 \\
\hline Formula 1 & 113076.92 & 55384.62 & 67692.31 & 198461.54 \\
Formula 2 & 106153.85 & 80769.23 & 75153.85 & 180153.85 \\
Formula 3 & 113076.92 & 60923.08 & 75846.15 & 222307.69 \\
Formula 4 & 106153.85 & 80446.15 & 72707.69 & 173923.08 \\
Formula 5 & 118153.85 & 70000.00 & 66153.85 & 168000.00 \\
\hline Rataan & 111323.08 & 69504.62 & 71510.77 & 188569.23 \\
Nilai ganti rugi & 6679384.62 & 3475230.77 & 3575538.46 & 9428461.54 \\
\hline
\end{tabular}


Dari hasil perhitungan dengan menggunakan kelima formula diperoleh nilai ganti rugi yang bervariasi untuk setiap jenis usaha, namun nilai penurunan pendapatan dari kelima formula relatif tidak berbeda jauh. Insiden pencemaran minyak telah menyebabkan penurunan pendapatan. Selama periode terdampak sekitar 60 hari diperoleh nilai total ganti rugi yang merupakan hasil perkalian dari lama dampak dengan nilai pendapatan yang turun. Selanjutnya, nilai pendapatan yang turun dan nilai ganti rugi selama periode terdampak dapat dilihat pada Tabel 3. Hasil perhitungan yang diperoleh untuk keempat jenis usaha masing-masing di objek wisata Pantai Tanjung Pakis hanya untuk satu orang pelaku usaha. Untuk mendapatkan nilai ganti rugi keseluruhan, usaha-usaha pariwisata memerlukan informasi jumlah pelaku usaha di lokasi objek wisata.

Perhitungan estimasi nilai ganti rugi dengan menggunakan nilai rataan dari kelima formulasi dilakukan untuk meminimalisasi overvalue, mengingat setiap orang cenderung menginginkan nilai ganti rugi yang lebih besar. Selain itu, pendapatan dari usaha pariwisata sangat bergantung pada jumlah pengunjung wisata yang kedatangannya dipengaruhi oleh hari libur dan hari-hari biasa. Pendapatan yang diperoleh pada hari libur sekitar 4 kali lipat dibandingkan dengan hari-hari biasa. Selanjutnya, hasil perhitungan dengan menggunakan formula tersebut dapat digunakan sebagai bahan pertimbangan pengambil keputusan secara lebih awal menyangkut estimasi besaran nilai ganti rugi. Setelah diketahui besaran ganti rugi, tentunya diperlukan tahapan selanjutnya antara lain verifikasi data masyarakat terdampak dan mekanisme pembayaran mengingat pembayaran ganti rugi berpegang pada prinsip by name dan by address agar tepat sasaran.

\section{SIMPULAN}

Pengembangan metode penilaian ganti rugi ekonomi akibat insiden pencemaran minyak di laut dilakukan melalui tahapan (1) melakukan identifikasi usaha-usaha pariwisata, (2) membangun konsep teoritik kampensasi, (3) menentukan dasar hukum perhitungan kompensasi, dan (4) mendesain formula ganti rugi. Penerapan lima formula perhitungan ganti rugi membutuhkan 18 variabel. Estimasi nilai ganti rugi diperoleh dengan cara merata-ratakan nilai kelima formula. Untuk studi kasus kegiatan pariwisata bahari di Pantai Tanjung Pakis, diperoleh estimasi nilai ganti rugi (Rp/hari) untuk usaha penyedia jasa pelampung sewaan Rp 111 323.08, penyedia jasa kamar mandi bilas Rp 69 504.62, pedagang makanan/minuman kecil Rp 71 510.77, dan pedagang makanan/minuman besar Rp 188569.23.

\section{UCAPAN TERIMA KASIH}

Penulis mengucapkan terima kasih kepada PHE ONWJ dan PPLH IPB dengan memberikan kesempatan melakukan survei lapangan.

\section{DAFTAR PUSTAKA}

[MEA] Millennium Ecosystem Assessment. 2005. Ecosystems and Human Wellbeing: Synthesis. Washington DC (US): World Resources Institute.

[Kemen LH] Kementerian Lingkungan Hidup. 2014. Peraturan Menteri Negara Lingkungan Hidup Nomor 7 tahun 2014 tentang Kerugian Lingkungan Hidup Akibat Pencemaran dan/atau Kerusakan Lingkungan Hidup. Jakarta (ID): Kemen LH.

Costanza R, Groot RD, Sutton P, Ploeg SVD, Anderson SJ, Kubiszewski I, Farber S, Turner RK. 2014. Changes in the global value of ecosystem services. Global Environmental Change. 26: 152-158.

Dahuri R, Rais J, Ginting SP, Sitepu MJ. 2008. Pengelolaan Sumberdaya Wilayah Pesisir dan Lautan secara Terpadu. Jakarta (ID): Pradya Paramita.

Djunaedi OS. 2011. Sumberdaya Perairan. Potensi, Masalah dan Pengelolaan. Bandung (ID): Widya Pandjadjaran.

Fandeli. 1996. Pengusahaan Ekowisata. Yogyakarta (ID): Pustaka Pelajar. 
Fauzan RA. 2018. Analisis pendapatan pelaku usaha pariwisata di Kabupaten Wonosobo [skrpisi]. Semarang (ID): Fakultas Ekonomi Universitas Diponegoro.

Firdaus M, Juliansyah H. 2019. Pengaruh objek wisata waduk terhadap pendapatan pedagang Desa Jeulikat Kecamatan Blang Mangatkota Lhokseumawe. Jurnal Ekonomika Indonesia. VIII(2): 57-64.

Liu S, Costanza R, Farber S, Troy A. 2010. Valuing ecosystem services. Theory, practice, and the need for a transdisciplinary synthesis. Ann NY Acad Sci. 1185: 54-78.

Mukhtasor. 2007. Pencemaran Pesisir dan Laut. Cetakan Pertama. Jakarta (ID): Pradnya Paramita.

Pemerintah Indonesia. 2009. Undang-Undang Nomor 10 Tahun 2009 tentang Kepariwisataan. Jakarta (ID): Sekretariat Negara.

Pemerintah Indonesia. 2009. Undang-Undang Nomor 32 Tahun 2009 tentang Perlindungan dan Pengelolaan Lingkungan Hidup. Jakarta (ID): Sekretariat Negara.

Soekadijo RG. 2000. Anatomi Pariwisata - Memahami Pariwisata sebagai "Systemic Linkage". Cetakan Ketiga. Jakarta (ID): Gramedia Pustaka Utama.

Spillane JJ. 1987. Ekonomi Pariwisata. Sejarah dan Prospeknya. Jakarta (ID): Kanasius.

Vihervaara P, Kumpula T, Tanskanen A, Burkhard B. 2010. Ecosystem services-A tool for sustainable management of human-environment systems. Case study Finnish Forest Lapland. Ecological Complexity. 7: 410-420.

Yoeti OA. 2008. Ekonomi Pariwisata. Introduksi, Informasi dan Implementasi. Jakarta (ID): Kompas Media Nusantara. 